\title{
GASOLINE PARTIALLY PREMIXED COMBUSTION : HIGH EFFICIENCY, LOW NOX AND LOW SOOT BY USING AN ADVANCED COMBUSTION STRATEGY AND A COMPRESSION IGNITION ENGINE
}

\author{
Vittorio MANENTE \\ Lund University \\ vittorio.manente@energy.lth.se
}

\author{
Bengt JOHANSSON \\ Lund University \\ Pert TUNESTAL \\ Lund University
}

\author{
Marc SONDER \\ ETH Zurich \\ msonder@student.ethz.ch
}

\begin{abstract}
A VOLVO D5 was ran with Gasoline in order to demonstrate that high octane number fuels, in compression ignition engines, are able to achieve high efficiency, low NOx and low soot at the same time in the whole load range. An advanced injection strategy was developed to accomplish the target. It consisted in injecting most of the fuel very early in the compression stroke and then through the stratification created by the last injection the combustion is triggered. The load is controlled with the first injection while the combustion phasing with the last.

Running the engine at $2000 \mathrm{rpm}$, an IMEP sweep was performed between 6 and 17 bar IMEP. Up to 8 bar IMEP no EGR are needed to keep NOx and soot below 27 ppm and 0.05 FSN respectively. After this load EGR is increased up to 50\%, soot and NOx are still below the previously mentioned values while the gross indicated efficiency stays fairly constant at $47 \%$ throughout the sweep. In the second section of the paper, Diesel was compared with Gasoline. Slightly higher efficiency was obtained with the lower octane number fuel, NOx was comparable and soot steadily increased during the IMEP sweep up to 9 FSN. In the final part of the research, the commercial $140^{\circ}$ UA nozzle was compared to the narrower one, $120^{\circ}$, that was used in the above mentioned experiments. Comparable values of soot and NOx are achieved on the other hand the efficiency deteriorates because the hot areas of the combustion move closer to the wall.
\end{abstract}

\section{INTRODUCTION}

Partially premixed combustion, PPC, is a hybrid concept between HCCI and diffusion combustion. Fuel is injected relatively early in the cycle, then by various means [1-8] the ignition delay is increased until sufficient separation has been achieved between the end of injection and the start of combustion; combustion takes place around TDC. The target of the PPC concept is a contemporary reduction of NOx and soot; NOx is reduced by decreasing the combustion temperature while soot by achieving low stratified mixture when combustion starts. As shown by [7], Diesel PPC is able to work up to 15 bar BMEP unfortunately by increasing the load, up to $80 \%$ of EGR is needed to separate the end of injection with the start of combustion, in addition the indicated efficiency deteriorates because of the deterioration of the combustion efficiency.

In 2006 Kalghatgi showed that by injecting Gasoline in a compression ignition engine low NOx, low soot and high efficiency can be achieved at the same time up to 13 bar IMEP [9, 10]. Following the path traced by Kalghatgi, the authors published three papers on the behavior of high octane number fuels in a heavy duty compression ignition engine [11-13]. To achieve smooth engine operations, low NOx, low soot and high efficiency, the authors developed an injection strategy similar to UNIBUS [8]. The injection strategy consisted in injecting a large amount of fuel early during the compression stroke and then the combustion is triggered by the stratification created by a second injection around TDC. As the load increases EGR is added to avoid preignition of the fuel belonging to the first injection. In 2009 Kalghatgi demonstrated the viability of running Gasoline in a light duty compression ignition engine [14]. Low NOx and low soot were achieved on the other end the efficiency was slightly lower as compared to his previous results.

In this paper the injection strategy developed by the authors was implemented in a light duty VOLVO D5 engine. By using a narrow nozzle umbrella angle, an IMEP sweep was done between 6 and 17 bar gross IMEP in order to demonstrate the viability of the concept and what inlet conditions are necessary to attain low NOX, low soot and high efficiency. In the second part of the paper a comparison was carried out between Diesel and Gasoline PPC to show the limitations of the low octane number fuel at high load. In the last section of this research the customs D5 nozzle was compared to the narrow umbrella angle one to demonstrate that if combustion takes place in a smaller region of the combustion chamber, heat transfer can be reduced without penalizing NOx or soot.

\section{EXPERIMENTAL SET UP}

The engine used during the experiments is a five cylinders production VOLVO D5 modified to run with only one cylinder. The fuel was injected with a common rail injection system from Bosch; the nozzle umbrella angle 
was 120 degrees instead of the production $140^{\circ}$ degrees. The engine specifications can be found in Hata! Bakuru kaynaĵ ēbulunamadē.

Table 2: Test engine specifications.

\begin{tabular}{|c|c|}
\hline Displaced volume & $1920 \mathrm{cc}$ \\
\hline Stroke & $92.3 \mathrm{~mm}$ \\
\hline Bore & $81 \mathrm{~mm}$ \\
\hline Geom. comp. ratio & $16.15: 1$ \\
\hline Injection Cone & $120^{\circ}$ \\
\hline Injector Type & Solenoid \\
\hline $\begin{array}{c}\text { Nozzle } \\
\text { (number x diameter) }\end{array}$ & $7 \times 0.14 \mathrm{~mm}$ \\
\hline
\end{tabular}

The experimental set-up is presented in Figure 1. High inlet pressures were achieved by supplying compressed air with an external compressor. In order to use high EGR rates the back pressure had to be raised 0.2 bar higher than the intake one by throttling the exhaust, thus forcing exhaust gases into the intake manifold if the EGR valve was opened. The EGR rate was calculated as the ratio of $\mathrm{CO}_{2}$ in the intake and in the exhaust. The inlet temperature was measured at the entrance of the intake manifold with a $\mathrm{K}$ type thermocouple; a PID regulator was used to keep the temperature at the desired value.

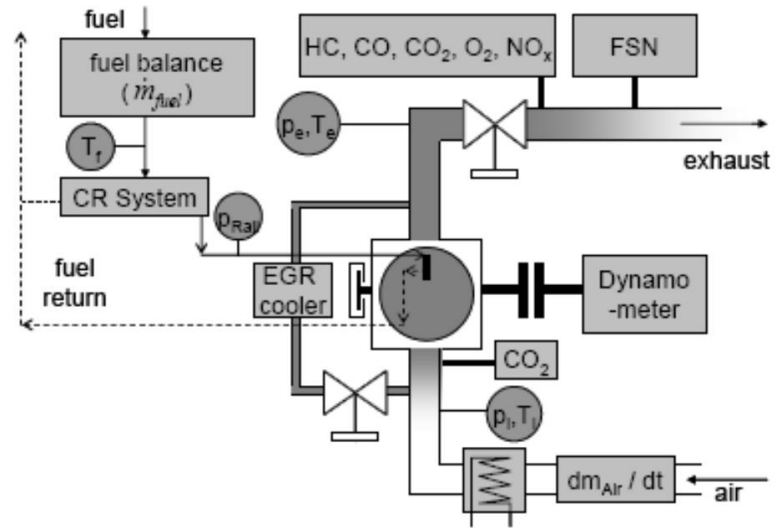

Figure 1: Schematic experimental set-up.

The emissions were measured as follow. By using a Maihak $S 710$ system, $\mathrm{CO}$ and $\mathrm{CO}_{2}$ were measured by nondispersive infrared analyzer, $\mathrm{O}_{2}$ with a paramagnetic analyzer and total $\mathrm{HC}$ with a heated flame ionization detector from JUM. A chemiluminescent analyzer was used for NOx (ECO Physics CLD 700 EL unit) and the smoke was measured with an AVL 415S opacimiter. Each analyzer was calibrated with an appropriate calibration gas before every set of measurements.

The fuel mass flow was measured by a fuel balance (Sartorius cp8201) over a time span of 180 seconds; the engine efficiency calculations are based on the measured fuel flow. The airflow was estimated using $\lambda$ (from the exhaust gas analysis) and the fuel flow.

The cylinder pressure was measured with a piezoelectric pressure sensor (Kistler 6056) at the sample rate of $0.2^{\circ}$ CAD; the data were averaged over 150 engine cycles.

\section{FUELS}

In this research two fuels were used: low-sulphur Gasoline (Swedish 98 Octane) and Diesel (Swedish MK1). The fuel properties can be found in Hata! Bakuru kaynaj ēbulunamadē.

Table 3: Fuels Properties.

\begin{tabular}{|l|l|l|l|}
\hline & CN [-] & RON [-] & LHV [MJ/kg] \\
\hline Gasoline & - & 98.0 & 44.3 \\
\hline Swedish MK1 & 51.3 & - & 42.5 \\
\hline
\end{tabular}

\section{EXPERIMENTS}

Three sets of experiments were carried out. 
- $\quad$ IMEP sweep between 6.58 and 16.99 bar gross IMEP. The inlet temperature was adjusted to maximize the efficiency while the boost to introduce much EGR and keep $\lambda$ above 1.5; see Figure 2 and Figure 3. The engine speed was set at $2000 \mathrm{rpm}$ while the injection pressure at $1400 \mathrm{bar}$.
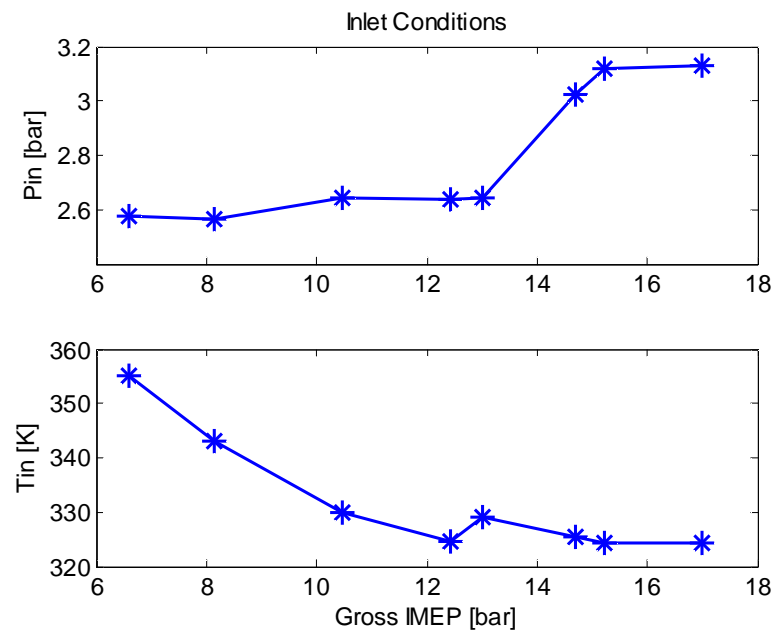

Figure 2: absolute inlet pressure and inlet temperature as a function of load.
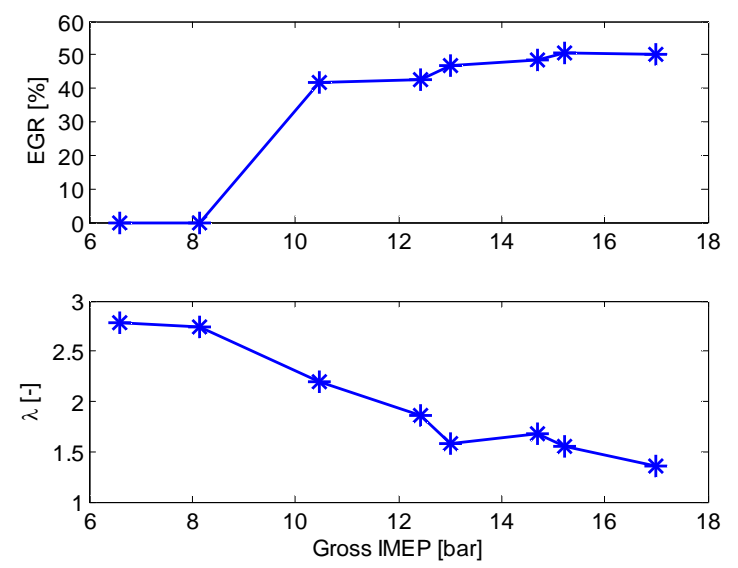

Figure 3: EGR and $\lambda$ as a function of load.

- Comparison between Diesel and Gasoline. The two fuels were compared in the load range between 12 and 17 bar IMEP. The inlet conditions were kept constant while Diesel injection strategy was modified (see section: ñIMEP Sweeps: Diesel compared with Gasolineò) together with the umbrella angle (commercial nozzle, $140^{\circ}$ ).

- Comparison of the $120^{\circ}$ and $140^{\circ}$ degrees umbrella angle nozzles; the fuel used was Gasoline. The comparison was carried out between 12 and 17 bar IMEP and the inlet conditions were held constant.

\section{ADVANCED INJECTION STRATEGY}

To successfully run Gasoline in CI engine an advanced injection strategy was developed. Following the path traced by the authors in [12], the idea is to create a fairly homogeneous mixture with the first injection and then trigger the combustion with the fuel stratification created by the second one. The load is mainly controlled by the fuel amount in the first injection thus EGR has to be added as load increases to avoid early ignition of the first injection. As compared to [12], a third injection pulse was added. In the D5 the authors noted that with only two pulses, the stratification created by the second injection was too high thus resulting in unacceptable pressure rise rate and knock. To mitigate the combustion rate an intermediate injection was added in order to reduce highly stratified mixture with the last pulse.

The three injections were placed at $-90,-55$ and -25 TDC. The load was controlled by adjusting the fuel amount in the first injection; increasing the load minor variations were done on the duration of the other two injection pulses (see Figure 4). Throughout the IMEP sweep the start of the three injections, SOI, was kept constant. 


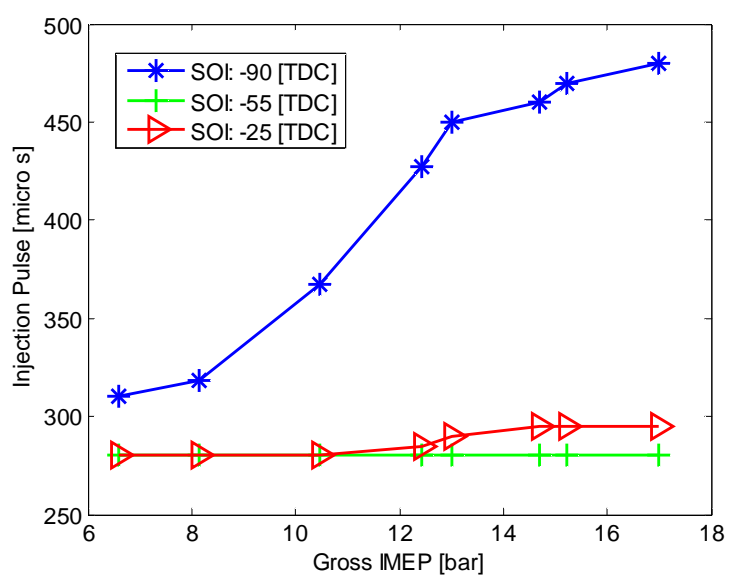

Figure 4: Injection pulse duration as a function of load.

The results of the implementation of this advanced injection strategy can be found in Figure 5. A separation was achieved between the end of third injection and the start of combustion. The long ignition delay allowed having a low stratified mixture at the beginning of the combustion which resulted in almost zero soot production even at high load (see Figure 12). The combustion rate was kinetically controlled which means that its speed is not anymore a function of the injection rate as in classical Diesel combustion; this means that with Gasoline the common rail pressure will be solely used to control soot production and not the engine efficiency. Kinetically controlled combustion is faster than the diffusion counterpart thus, with Gasoline, the efficiency can be improved because of the increase in the effective expansion ratio.

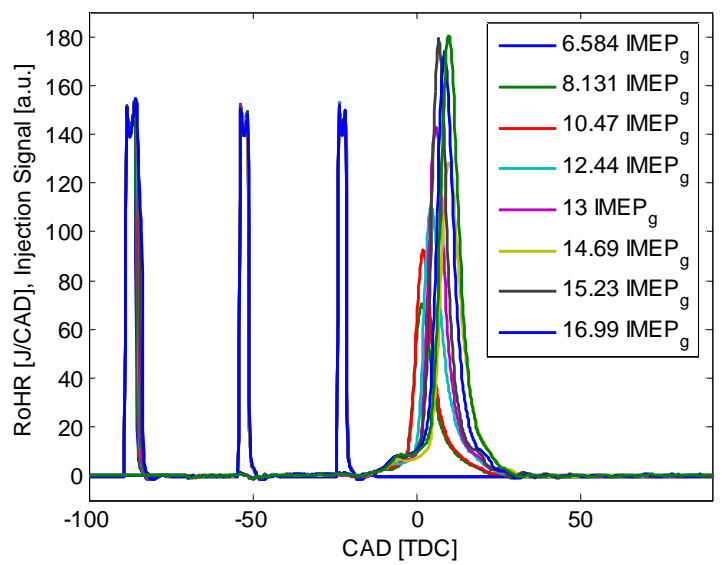

Figure 5: Rate of heat release and injection pulses as a function of load.

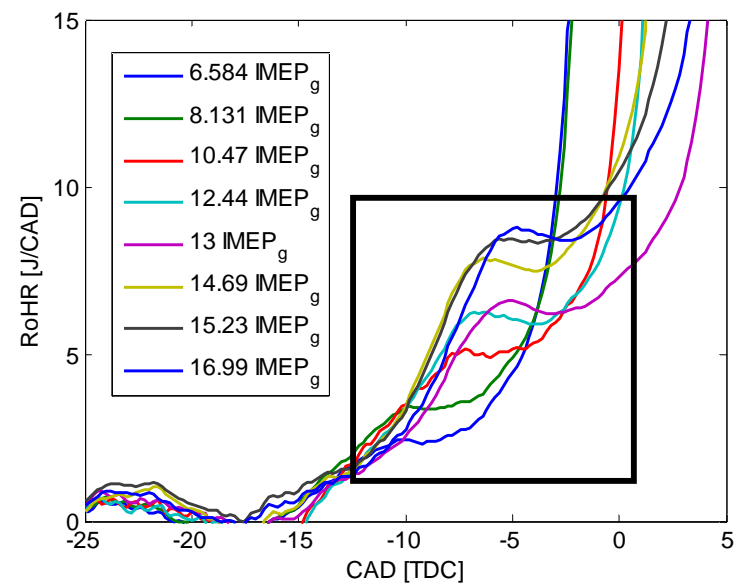

Figure 6: Low temperature reactions as a function of load. 


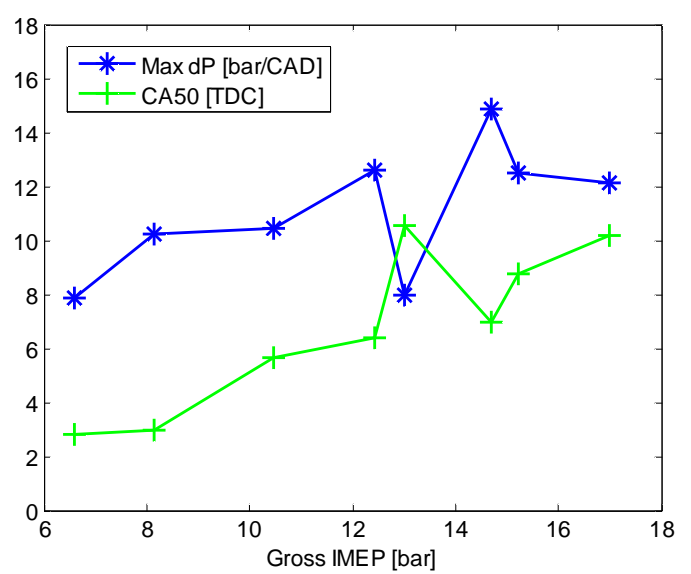

Figure 7: Maximum pressure rise rate and combustion phasing as a function of load.

One of the issues of kinetically controlled combustion is the maximum pressure rise rate at high load. Unacceptable values were avoided because of this advanced injection strategy; see Figure 7. Figure 6 shows the low temperature reactions, LTR, as a function of the load. Increasing the load the magnitude of the LTR increases thus high peak of maximum heat release can be avoided. It is though that the LTR comes mainly from reactions belonging to the first two injections.

\section{RESULTS}

\section{IMEP SWEEP}

The paragraph shows an IMEP sweep between 6 and 17 bar gross IMEP. The section is divided in two parts; in the first one the three efficiencies are analyzed while in the second the emissions.

Efficiency

The three efficiencies as a function of load are presented in Figure 8. The gross indicated efficiency is fairly independent on load, on the other hand the thermal one decreases from 55 to $50 \%$ up to 13 bar IMEP and then stays flat. The combustion efficiency increases from 87 to $95 \%$ and then it remains constant between 13 and 17 bar IMEP. These two opposite trends compensate each other resulting in a fairly flat gross indicated efficiency trace.

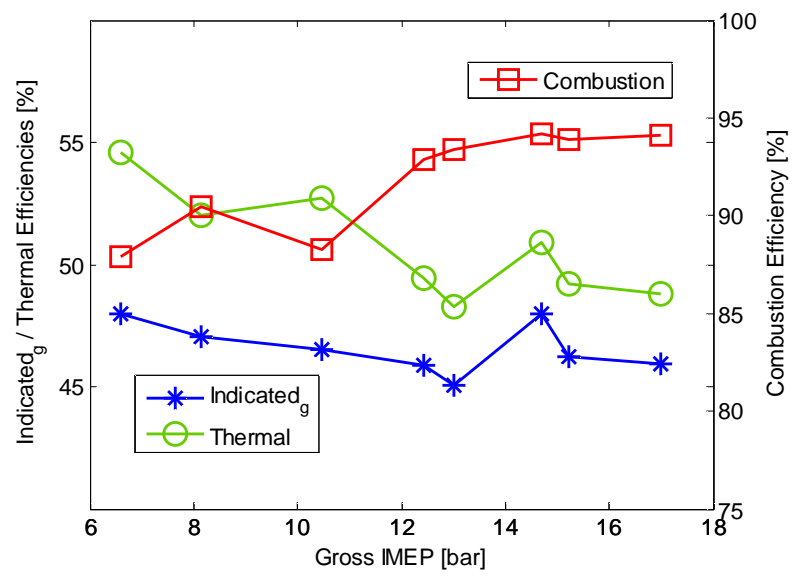

Figure 8: Gross indicated, thermal and combustion efficiencies as a function of load.

The behavior of the combustion efficiency can be explained considering the cycle temperature. Increasing the load the cycle temperature increases thus the combustion efficiency; see the maximum cycle temperature in Figure 11.

To explain the trend of the thermal efficiency requires more detailed analysis. The thermal efficiency is influenced by two parameters: heat transfer and exhaust loss. The heat transfer is a function of the gradient 
between wall and bulk gas temperatures, and the convection coefficient of the matter between these two temperatures. The exhaust loss depends solely on the effective expansion ratio once the combustion is over.

In order to analyze the effects of the heat transfer and exhaust loss on the thermal efficiency, the first law of the thermodynamic was applied to the combustion volume: ${ }^{1}$

$$
\begin{aligned}
& F U E L_{-} M E P=I M E P_{\text {gross }}+\text { Emission }-M E P+ \\
& + \text { Heat }_{-} \text {Transfer_ } M E P+\text { Exhaust }{ }_{-} M E P
\end{aligned}
$$

The relative ${ }^{2}$ Heat Transfer MEP and the relative Exhaust MEP are plotted in Figure 9. The relative heat transfer increases between 6 and 13 bar gross IMEP and then stays constant; the relative exhaust loss is fairly flat. The variation in heat transfer rather than the behavior of the exhaust loss is the main responsible for the thermal efficiency trend.
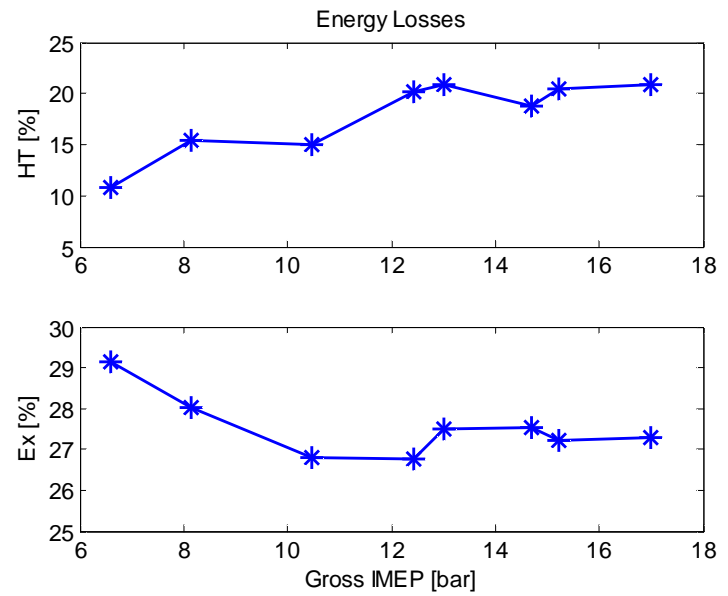

Figure 9: Relative heat transfer and exhaust loss as a function of IMEP.

It is thought that the relative exhaust loss has a flat behavior because of a constant expansion ratio. This was achieved by keeping the combustion duration roughly constant throughout the IMEP sweep; see Figure 10.

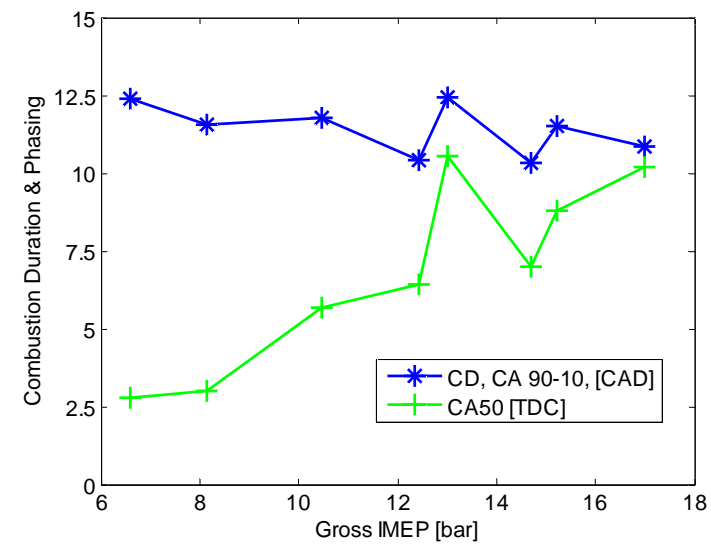

Figure 10: Combustion duration and combustion phasing as a function of load.

It is now important to clarify how it was possible to achieve low relative heat transfer throughout the IMEP sweep. It is thought that with this narrow spray angle, most of the combustion is confined in the bowl volume; a proof of this hypothesis is the low mass averaged maximum combustion temperature (Figure 11). Because most of the combustion occurs in the bowl, the hot areas are relatively far from the wall thus the heat transfer is reduced. This is just a reasonable hypothesis that needs to be clarified with optical diagnostic experiments.

\footnotetext{
${ }^{1}$ The terms in Equation 1 are expressed in bar since the energy has been divided with the displacement volume. This can allow an easier comparison among engines of different sizes.

2 The relative quantity of the terms in Equation 1 is defined as the mean effective values divided with the Fuel MEP. This facilitates the comparison of the three losses as a function of the load.
} 

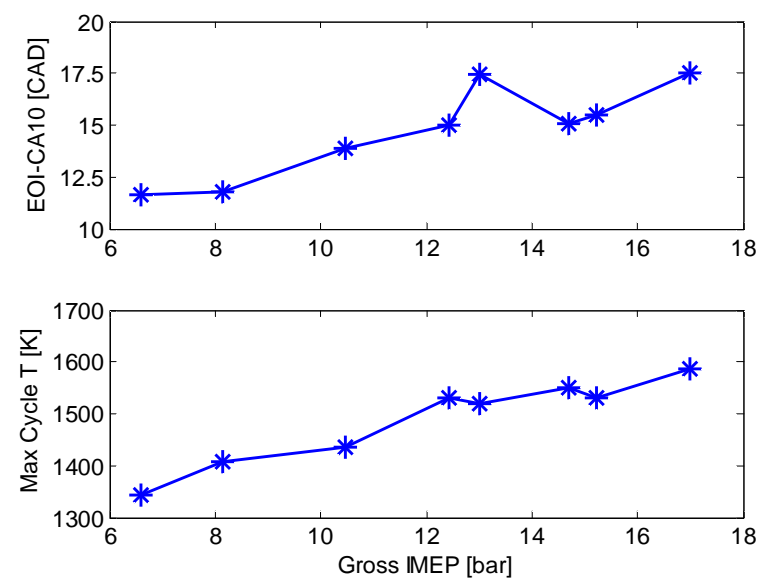

Figure 11: Ignition delay and maximum cycle temperature as a function of load.

\section{$\underline{\text { Emissions }}$}

Very low soot and NOx emissions were achieved in a broad load range; see Figure 12. In the load range of $5 \mathrm{i}$ 10.5 bar IMEP, where no EGR was used NOx were below $20 \mathrm{ppm}$. This was possible because of the long and positive ignition delay of Gasoline. Because the start of combustion was some crank angles after the end of injection, it was possible to avoid rich areas inside the combustion chamber thus high local temperature that would have resulted in high NOx level. After 10.5 bar IMEP EGR was added up to roughly $50 \%$. EGR accomplished a double function: reducing the peak combustion temperature and lowering the mixture reactivity (longer ignition delay). By adding EGR, it was possible to keep a long ignition delay and low combustion temperature that resulted in less than $20 \mathrm{ppm}$ of NOx up to 17 bar IMEP.

The long ignition delay thus the relatively homogeneity of the mixture when combustion started led to low soot production, below $0.1 \mathrm{FSN}$, even when $50 \%$ of EGR was used.
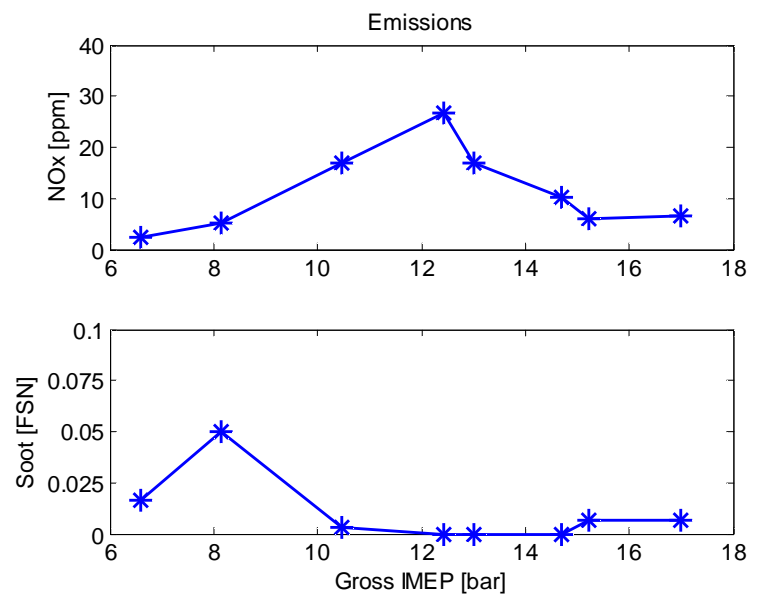

Figure 12: NOx and soot emissions as a function of load and umbrella angle.
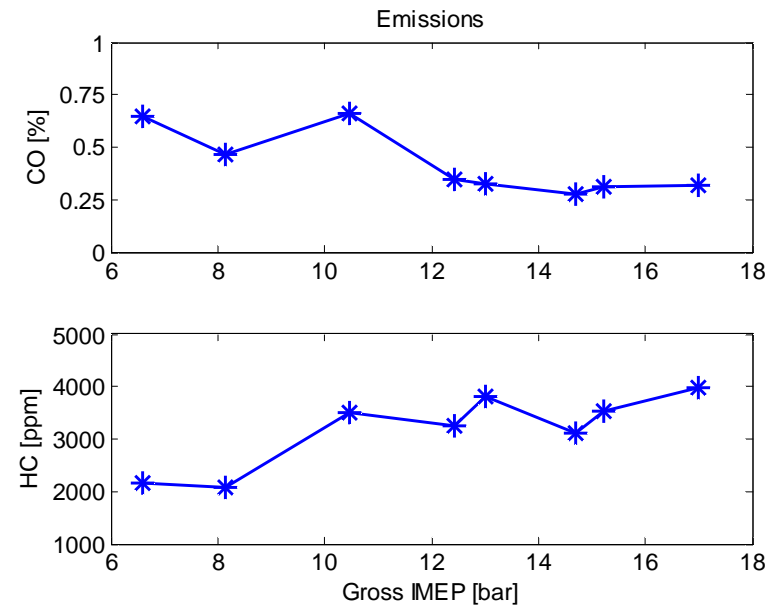

Figure 13: $\mathrm{CO}$ and $\mathrm{HC}$ emissions as a function of load and umbrella angle. 
$\mathrm{CO}$ and $\mathrm{HC}$ are presented in Figure 13. As compared to standard Diesel combustion these two emissions show high values thus resulting in low combustion efficiency; see Figure 8.

By increasing the load $\mathrm{CO}$ decreases even when EGR was added; this was the result of higher combustion temperature (see Figure 11). HC, on the other hand, shows the opposite trend. This was caused by the fact that the load was increased by increasing the fuel amount in the first injection.

\section{IMEP SWEEPS: DIESEL COMPARED WITH GASOLINE}

This advanced injection strategy, developed for running Gasoline in a CI engine, was compared with Diesel combustion. To allow a fair comparison, the Diesel injection strategy consisted in injecting $10 \%$ of the total fuel amount in the pilot at -10 TDC while the main was adjusted to control the load and the combustion phasing; the use of the exact the same injection strategy would have led to too early ignition of Diesel. Inlet conditions, on the other hand, were kept the same for both fuels.

As it can be seen in Figure 14, the use of much EGR, up to $50 \%$, was able to separate the end of the main injection with the start of the combustion even in the case of Diesel. The ignition delay is presented in Figure 15; the positive ignition delay of Diesel suggests that when the combustion starts the mixture is premixed but highly stratified. The highly stratified premixed combustion explains the shape of the heat release rate that is not bell shaped as in the case of Gasoline.
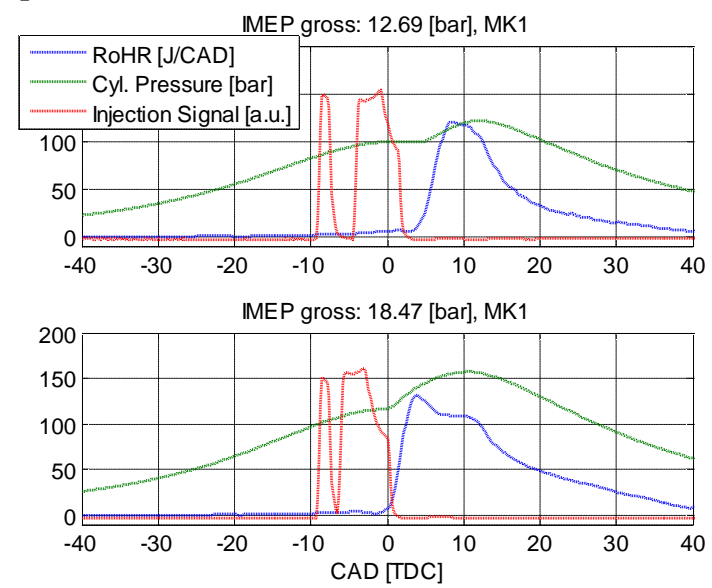

Figure 14: Cylinder pressure, heat release rate and needle lift at maximum and minimum tested load points.

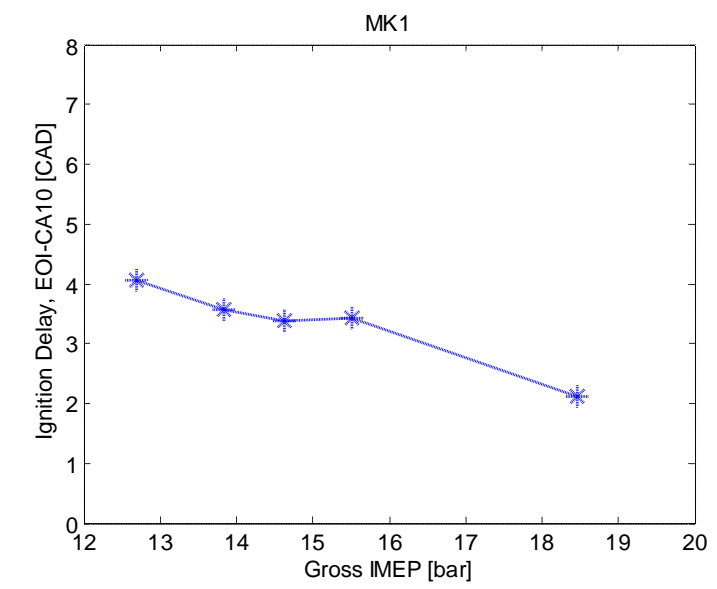

Figure 15: Ignition delay for MK1 as a function of load.

The three efficiencies as a function of load are plotted for Diesel and Gasoline. Diesel shows higher gross indicated efficiency throughout the load range both because of higher thermal and combustion efficiencies. In the case of Diesel a drop in indicated efficiency can be observed after 15.5 bar IMEP; a fast decrease in combustion efficiency explains the trend (the thermal efficiency is relatively flat). 

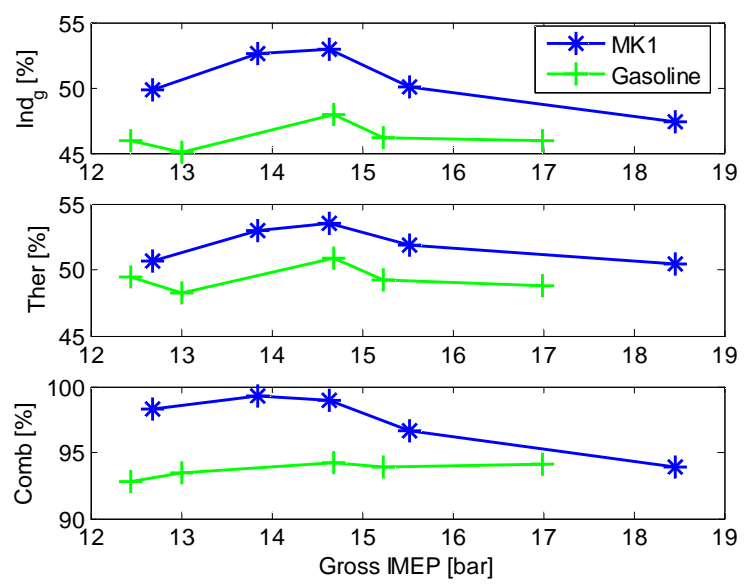

Figure 16: Gross indicated, thermal and combustion efficiencies as a function of load.

The relative energy losses are shown in Figure 17. Figure 17 suggests that Diesel has higher gross indicated efficiency than Gasoline both because of the lower heat transfer and combustion losses. As explained in the section ñIMEP Sweepò low heat transfer is achieved because most of the combustion takes place in the bowl thus the hot areas are distant from the cylinder wall. Up to 15.5 bar IMEP Diesel shows low combustion loss as a result of the low $\mathrm{CO}$ and $\mathrm{HC}$ production; see Figure 21.
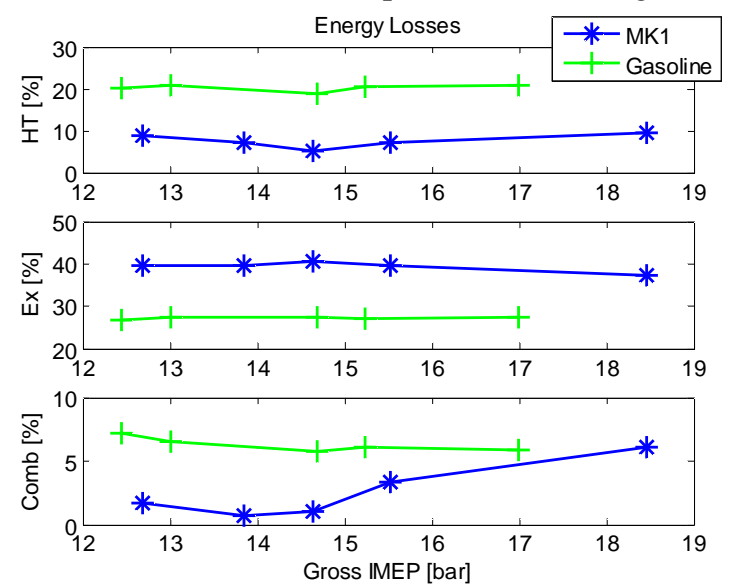

Figure 17: Relative heat transfer, exhaust and combustion losses as a function of load.

The main drawback of Diesel is the high exhaust loss. As it can be seen in Figure 18 the combustion duration of Diesel is much longer than in the Gasoline case, this results in lower expansion ratio that means higher exhaust temperature.
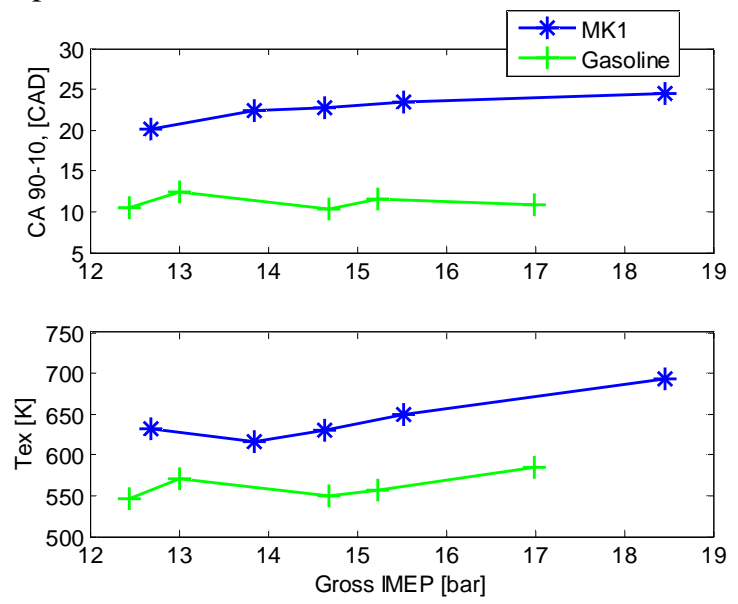

Figure 18: Combustion duration and exhaust temperature as a function of load.

NOx and soot emissions are displayed in Figure 19. Because EGR is able to decrease the combustion temperature (see Figure 20), comparable values of NOx can be seen both with Gasoline and Diesel. Gasoline 
shows slightly less NOx because of its longer ignition delay that results in more homogeneous mixture when combustion starts. In terms of soot Diesel shows unacceptable levels. This was the result of the combination of low combustion temperature and poor air fuel mixing (in the higher load case the ignition delay is only $1 \mathrm{CAD}$ ). Because of a bad air-fuel mixing and low combustion temperature, $\mathrm{CO}$ increases almost linearly after 14.5 bar IMEP up to $1 \%$ this resulted in a fast decrease in combustion efficiency. HC are low even at high load (much lower than Gasoline); this is suggesting that the cycle temperature is enough just to have reactions from fuel to $\mathrm{CO}$ but not from $\mathrm{CO}$ to $\mathrm{CO}_{2}$.
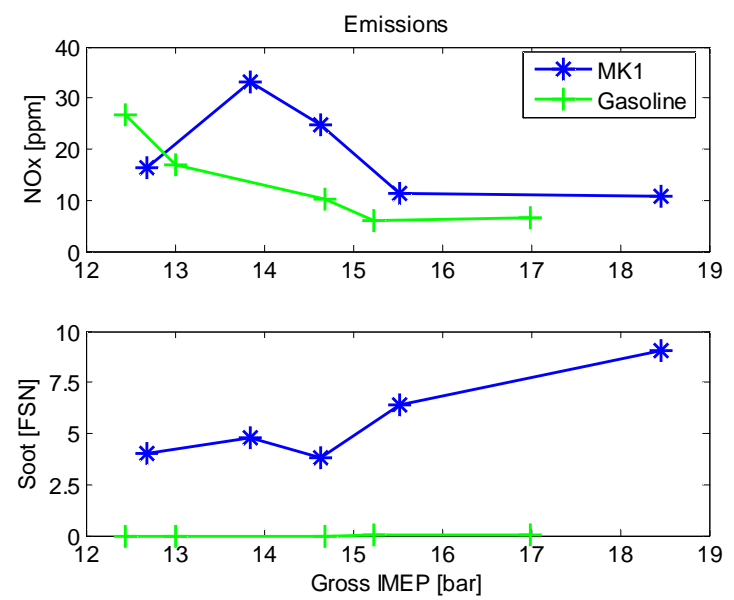

Figure 19: NOx and Soot as a function of load.

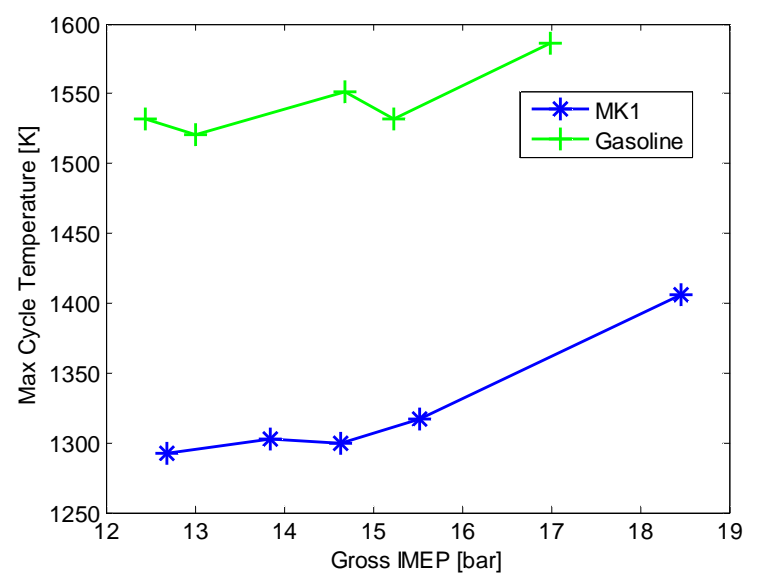

Figure 20: Maximum mass averaged cycle temperature as a function of load.
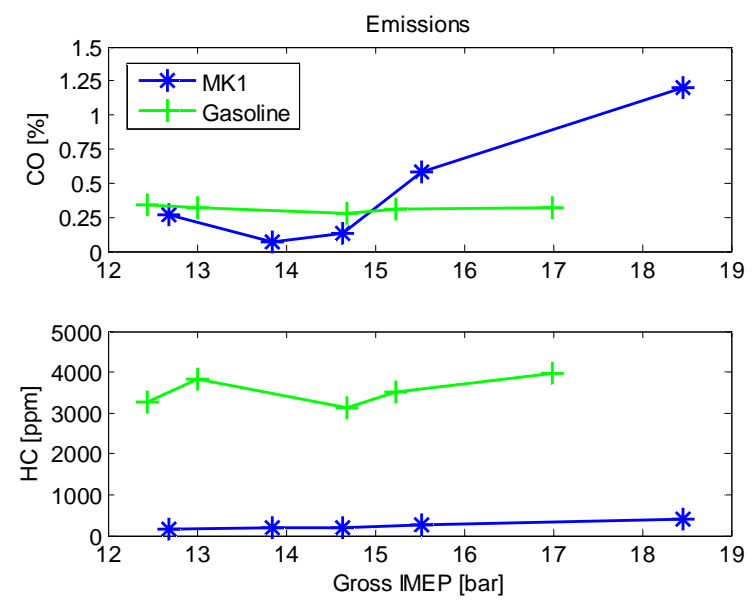

Figure 21: $\mathrm{CO}$ and $\mathrm{HC}$ as a function of load.

UMBRELLA ANGLE INFLUENCE: 140 VS. 120

The production D5 injector nozzle, 140 degree umbrella angle, was compared to the one used so far by the authors to study high ON fuels in a CI engine [11-13]. The comparison was carried out between 12 and 17 bar IMEP, the inlet conditions and the injection strategy were kept constant. In terms of NOx, Figure 22, the two 
nozzles show roughly the same values. Up to 15 bar IMEP soot are higher with the $140^{\circ}$ UA nozzle, then the values are comparable. The ignition delay of the $140 \mathrm{deg}$ UA is longer than the 120 counterpart. This is suggesting two things: the production nozzle creates less stratification and more fuel is present in the squish area when combustion starts. Because of the higher concentration of fuel in the squish area: soot, $\mathrm{CO}$ and $\mathrm{HC}$ are higher with the standard D5 nozzle (see Figure 24).
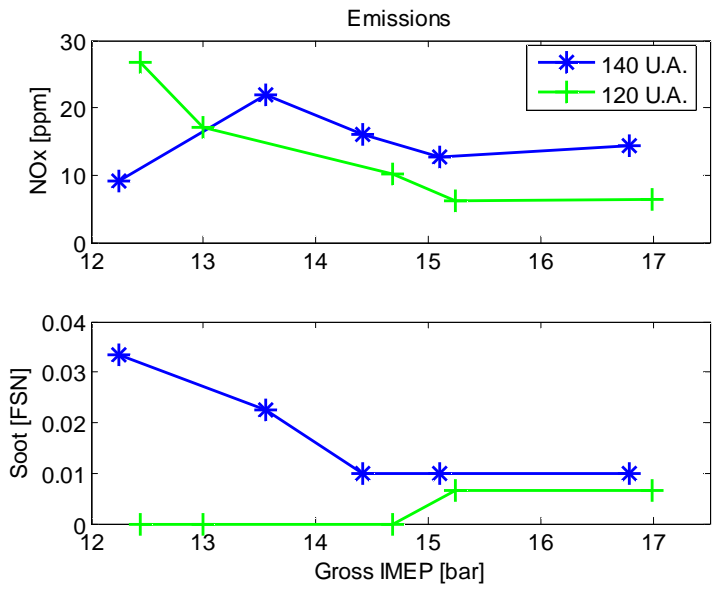

Figure 22: NOx and soot as a function of load and umbrella angle.

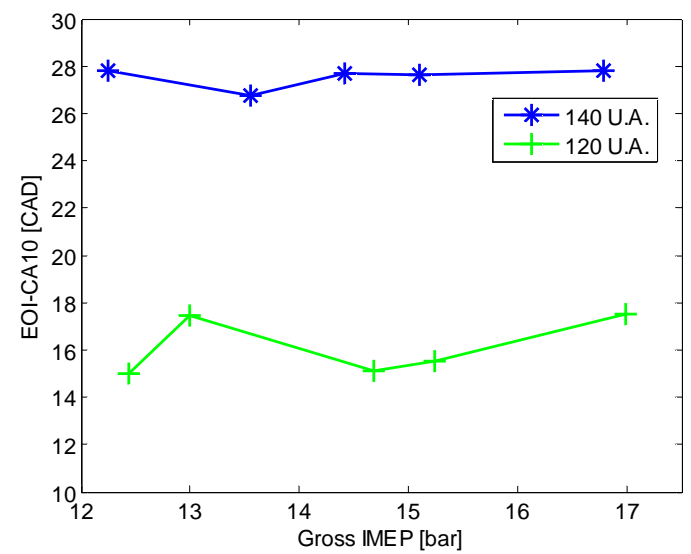

Figure 23: Ignition delay as a function of load and umbrella angle.
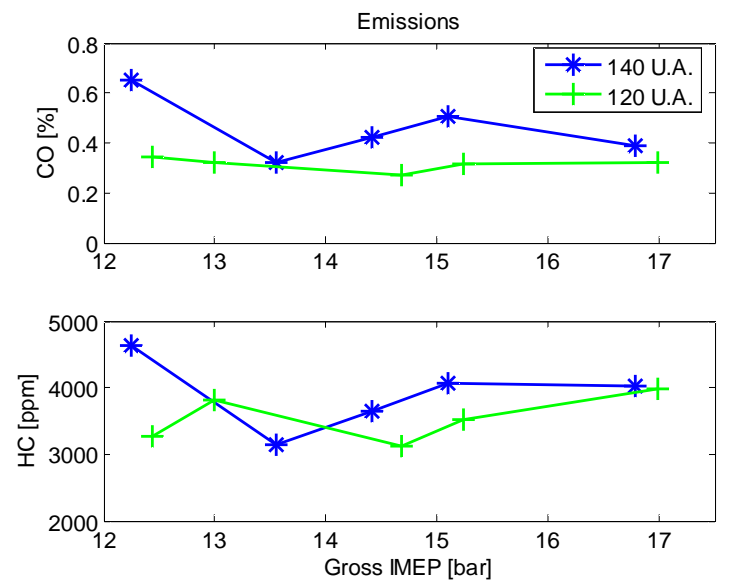

Figure 24: $\mathrm{CO}$ and $\mathrm{HC}$ as a function of load and umbrella angle.

The three efficiencies are presented in Figure 25. After 13.5 bar IMEP the gross indicated efficiency for the 140 deg. UA starts to decrease because of a deterioration of the thermal efficiency rather than a variation in combustion efficiency (its trace is fairly flat). 

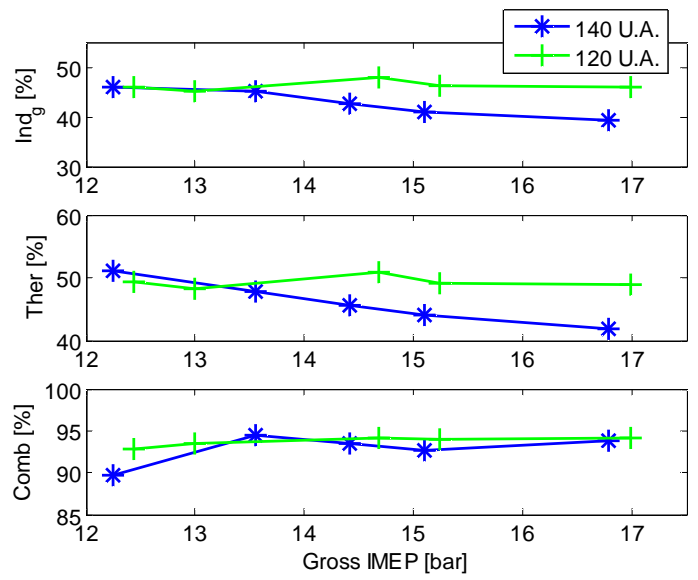

Figure 25: Gross indicated, thermal and combustion efficiencies as a function of load.

The relative energy losses displayed in Figure 26 indicates that the increase in heat transfer is the main responsible of the reduction in thermal efficiency. Considering that the load is controlled by the amount of fuel in the first injection and with $140 \mathrm{deg}$. UA more mixture goes in to the squish area, this founding is expected.
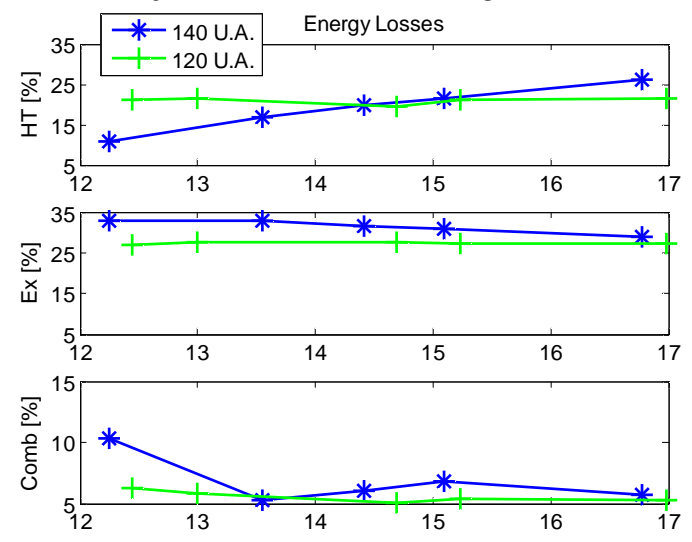

Figure 26: Relative heat transfer, exhaust and combustion losses as a function of load.

\section{DISCUSSION}

The current research highlighted that the use of Gasoline in a compression ignition engine is capable to achieve efficiency higher than $45 \%$ keeping soot and NOx to very low levels in the load range of 6 and 17 bar IMEP. These results were achieved thanks to an advanced injection strategy. It consisted in injecting most of the fuel very early in the compression stroke and then trough the stratification created by the last injection the combustion is triggered. The load is controlled with the first injection while the combustion phasing with the last.

There are several factors which contributed to successfully find an excellent compromise between efficiency and emissions:

- Kinetically controlled combustion.

- High injection pressure, small holes and narrow umbrella angle.

- Massive use of EGR.

- Ultra high boost.

The use of high octane number, ON, fuels such as Gasoline enable to have a fairly long ignition delay thus it is possible to separate the end of injection, EOI, with the start of combustion, SOC. Because the SOC occurs after the EOI, the combustion speed is a function of the reaction rate. Fast combustion means to increase the expansion ratio thus the efficiency of the engine is improved. High octane number fuels also allow the use of high compression ratio thus the expansion ratio can be further increased. It has been shown that, depending on the load, the optimum combustion duration lies between 10 and 30 CAD [15]. Having infinite fast combustion (Otto cycle), in real life applications, would lead to a thermodynamic disaster. With extremely fast combustion, e.g. $1 \mathrm{CAD}$, the combustion temperature is very high thus most of the thermal energy is lost in heat transfer. In addition knock can be experienced thus the heat transfer is further enhanced because the thermal boundary layer 
breaks [16, 17]; this was experienced by the authors in [11, 12]. In addition to this thermodynamic inconvenience high acoustic noise and more friction is experienced. For issues related to the heat transfer, the CA50, depending on the load, has to be also placed between 5 and 15 CAD after TDC [18].

In a CI engine using Diesel, high injection pressure and smaller holes are important because of the increase in mixing rate and the reduction of the fuel drops diameters that results in lower soot production and higher efficiency (the combustion is fuel rate controlled) $[19,20]$. In the case of Gasoline the mixing due to the high injection pressure has lower importance because of longer ignition delay due to its high $\mathrm{ON}$ thus the injection pressure can be reduced as compared to Diesel. In the case of Gasoline relatively high injection pressure and smaller holes are needed to increase the atomization of the fuel spray thus to achieve near zero soot as it has been shown in this research. In terms of injection system, high efficiency was achieved because of a narrow spray angle that allowed containing most of the combustion inside the bowl thus avoiding the hot area to be close to the wall (the heat transfer is reduced).

With high ON fuels a massive amount of EGR (up to 50\% as in this study) is needed at high load in order to decrease the combustion temperature (in the Diesel case, EGR is also used to increase the ignition delay). Lower combustion temperature has two positive consequences: thermal NOx production decreases and the heat transfer is reduced because of the lower temperature gradient between bulk gas and combustion chamber wall. High EGR rate increases $\mathrm{CO}$ and $\mathrm{HC}$ production thus the combustion efficiency is penalized [7]. In this study at 17 bar IMEP, 50\% of EGR did not deteriorate the combustion efficiency as in [7], undermixing and overmixing arguments, as in [21], might partially explain this behavior; this aspect is still under examination.

The last aspect that contributed to these good results is the high boost level. As shown in this research boosting contributes to keep the power density of the engine even when much EGR is used. High boost level increases also the specific heat ratio thus the expansion work increases. In addition with higher boost the heat transfer is reduced. When the inlet pressure increases, the mass inside the cylinder increases thus the internal energy of the combustion volume. The convective heat transfer is a function of the temperature gradient between the bulk gas and the wall; this gradient is mainly a function of the load. This means that increasing the boost the internal energy increases while the heat transfer stays constant thus resulting in higher output work.

This research underlined two main issues:

- Low load operations.

- Maximum pressure rise rate.

Below 10 bar IMEP too high inlet temperatures and pressures are required in order to keep the combustion going on. This founding suggests that below this load point a viable way has to be found in order to ignite the fuel-air mixture. One possible alternative might be NVO spark assisted operations that have been extensively studied in the last few years.

The second drawback of this concept is represented by the maximum pressure rise rate that in a passenger car should be below $5 \mathrm{bar} / \mathrm{CAD}$. To overcome this problem the most effective way is to retard the combustion phasing; the main drawback of this solution is a reduction in efficiency.

\section{CONCLUSIONS}

In this study the viability of running Gasoline in a compression ignition engine has been shown. This advanced combustion process offers very high efficiency, low NOx and low soot emissions at the same time; this was possible thanks to a newly developed injection strategy. Three experiments were carried out:

1. IMEP sweep between 6 and 17 bar gross IMEP with $120^{\circ}$ UA nozzle.

2. Comparison of Diesel and Gasoline in the IMEP rage of $12 \mathrm{i} 17 \mathrm{bar}$.

3. Influence of the umbrella angle, $140^{\circ}$ vs. $120^{\circ}$, in the IMEP rage of 12 ï $17 \mathrm{bar}$.

The conclusions that can be withdrawn from this research are the following. IMEP Sweep

- In the above mentioned IMEP range, the gross indicated efficiency trace is fairly flat and always higher than $45 \%$.

- The thermal efficiency has a peak of 55\% at 6 bar IMEP then it decreases and remains fairly constant between 48 and $50 \%$.

- The combustion efficiency lies between 92 and $94 \%$ for load higher than 12 bar IMEP, below this point it drops down to $88 \%$ at 6 bar IMEP.

- NOx is always between 2 and $17 \mathrm{ppm}$, only in one point it reaches $27 \mathrm{ppm}$.

- Soot is always below 0.05 FSN

- $\mathrm{CO}$ and $\mathrm{HC}$ show relatively high values but within acceptable range to be reduced with a conventional oxidation catalyst.

Comparison of Diesel and Gasoline

- As a result of lower heat transfer, in the IMEP range under examination, in average, Diesel has a gross indicated efficiency $10 \%$ higher than Gasoline. 
- Because of the low temperature combustion Diesel and Gasoline have comparable values of NOx; slightly lower in the second case.

- In the Diesel case, soot steadily increases up to 9 FSN as the load is increased. With Gasoline soot are always below 0.007 FSN.

- With a massive use of EGR, CO is comparable for the two fuels up to 15 bar IMEP after this point it reaches $1.2 \%$ at 18.5 bar IMEP with Diesel while it stays constant at $0.3 \%$ with Gasoline.

- $\mathrm{HC}$ are fairly steady throughout the sweep for both fuels. Gasoline shows values between 10 and 22 times higher than Diesel.

Comparison of the two nozzles

- The custom D5 nozzle shows lower gross indicated efficiency than the narrow one. The gap increases with load as the result of higher heat transfer.

- NOx and soot show comparable values but slightly lower in the narrow umbrella angle case.

- On an average base, $\mathrm{HC}$ and CO are 12 and $46 \%$ respectively lower with the $120^{\circ}$ umbrella angle injector nozzle.

\section{ACKNOWLEDGMENTS}

The author would like to acknowledge the Competence Center Combustion Processes, KCFP, for the financial support and Sonder Marc for running most of the experiments.

\section{REFERENCES}

Akihama, K., Takatori, Y., Inagaki, K., Sasaki,S., and Dean, A. M., Mechanism of the Smokeless Rich Diesel Combustion by Reducing Temperature, presented at SAE World Congress, 2001-01-0655, 2001.

Shimazaki, N., Tsurushima, T., and Nishimura,T., Dual Mode Combustion Concept with Premixed Diesel Combustion by Direct Injection Near Top Dead Center, presented at SAE World Congress, 2003-01-0742, 2003.

Okude, K., Mori, K., Shiino, S., and Moriya, T., Premixed Compression Ignition (PCI) Combustion for Simultaneous Reduction of NOx and Soot in Diesel Engine, presented at SAE Fuels and Lubricants Meeting, 2004-01-1907, 2004.

Minato, A., Tanaka, T., and Nishimura, N., Investigation of Premixed Lean Diesel Combustion with Ultra High Pressure Injection, presented at SAE World Congress, 2005-01-0914, 2005.

Kanda, T., Hakozake, T., Uchimoto, T., Hatano,J., Kitayama, N., and Sono, H., Ultra-Clean Combustion Technology Combining a Low-Temperature and Premixed Combustion Concept for Meeting Future Emission Standards, presented at SAE World Congress, 2005-01-0378, 2005.

Musculus, Mark P. B., Multiple Simultaneous Optical Diagnostic Imaging of Early-Injection Low-Temperature Combustion in a Heavy-Duty Diesel Engine, presented at SAE World Congress, 2006-01-0079, 2006.

Andersson M. et al., Characterization of Partially Premixed Combustion, presented at Powertrain \& Fluid Systems Conference, 2006-01-3412, 2006.

Hasegawa R., Yanagihara H., HCCI Combustion in DI Diesel Engine, presented at SAE World Congress, 200301-0745, 2003.

Kalghatgi G., Risberg P., Angstrom H., Advantages of Fuels with High Resistance to Auto-ignition in Lateinjection, Low-temperature, Compression Ignition Combustion, presented at Powertrain \& Fluid Systems Conference, 2006-01-3385, 2006.

Kalghatgi G., Risberg P., Angstrom H., Partially Pre-Mixed Auto-Ignition of Gasoline to Attain Low Smoke and Low NOx at High Load in a Compression Ignition Engine and Comparison with a Diesel Fuel, presented at 2007 Fuels and Emissions Conference 2007-01-0006, 2007.

Manente V., et al., Half Load Partially Premixed Combustion, PPC, with High Octane Number Fuels. Gasoline and Ethanol Compared with Diesel, presented at ARAIINDIA 2009, 295, 2009.

Manente V., et al., Partially Premixed Combustion at High Load using Gasoline and Ethanol, a Comparison with Diesel, presented at SAE World Congress, 2009-01-0944, 2009.

Manente V., et al. Characterization of Partially Premixed Combustion with Ethanol: EGR sweeps, Low and Maximum Loads, Proceedings of the ASME Internal Combustion Engine Division 2009 Spring Technical Conference, ICES2009-76165, 2009.

Kalghatgi et al., Low NOx and Low Smoke Operation of a Diesel Engine Using Gasoline Like Fuels, Proceedings of the ASME Internal Combustion Engine Division 2009 Spring Technical Conference, ICES2009-76034, 2009. 
Internal Combustion Engine, Bengt Johansson, 2006.

Tsurushima T., et al., The Effect of Knock on Heat Loss in Homogeneous Charge Compression Ignition Engines, presented at SAE 2002 World Congress, 2002-01-0108, 2002.

Tsurushima T., et al., Thermodynamic Characteristics of Premixed Compression Ignition Combustions, presented at International Spring Fuels \& Lubricants Meeting, 2001-01-1891, 2001.

Vressner A. et al., Combustion Chamber Geometry Effects on the Performance of an Ethanol Fueled HCCI Engine, presented at 2008 SAE International Powertrains, Fuels and Lubricants Congress, 2008-01-1656, 2008.

Dodge L. et al., Effect of Small Holes and High Injection Pressures on Diesel Engine Combustion, presented at SAE 2002 World Congress, 2002-01-0494, 2002.

Alfuso S. et al., Analysis of a High Pressure Diesel Spray at High Pressure and Temperature Environment Conditions, presented at SAE 2005 World Congress, 2005-01-1239, 2005.

Kook S., The Effect of Swirl Ratio and Fuel Injection Parameters on CO Emission and Fuel Conversion Efficiency for High-Dilution, Low-Temperature Combustion in an Automotive Diesel Engine, presented at SAE 2006 World Congress, 2006-01-0197, 2006.

\section{CONTACT}

Vittorio Manente

Lund University

Department of Energy Sciences

e-mail: vittorio.manente@energy.lth.se

\section{DEFINITIONS, ACRONYMS, ABBREVIATIONS}

\begin{tabular}{|l|l|}
\hline BMEP & Brake Mean Effective Pressure \\
\hline CA50 & $50 \%$ of total mass fuel burned \\
\hline CAD & Crank Angle Degree \\
\hline CD & Combustion Duration \\
\hline CI & Compression Ignition \\
\hline CO & Carbon monoxide \\
\hline EOI & End Of Injection \\
\hline HC & Hydrocarbons \\
\hline HCCI & Homogeneous Charge Compression Ignition \\
\hline$\lambda$ & Relative excess of air \\
\hline LTR & Low Temperature Reactions \\
\hline MEP & Mean Effective Pressure \\
\hline NOx & Nitrogen monoxide and dioxide \\
\hline ON & Octane Number \\
\hline PPC & Partially Premixed Combustion \\
\hline SOC & Start Of Combustion \\
\hline SOI & Start Of Injection \\
\hline TDC & Top Dead Center \\
\hline UA & Umbrella Angle \\
\hline
\end{tabular}

